\title{
Urban Heat Islands and Social Work: Opportunities for Intervention
}

\author{
Billy Hamilton \\ Christina L. Erickson
}

\begin{abstract}
The urban heat island (UHI), formed by surface modification of soil and vegetation, increases minimum nighttime temperatures within cities and causes heatstress among dwellers. Children, elders and low-income persons are disproportionately burdened by the UHI. These populations often lack the necessary biological, economic and social resources to cope with or prevent heat stress. Because UHI's are expected to increase with climate change, more social workers will be expected to serve the populations most affected by UHI. This paper addresses how the social work profession can play a role in efforts to address the effects of UHI's on vulnerable populations.
\end{abstract}

Keywords: Urban heat island, environmental justice, heat stress, climate change

\section{INTRODUCTION}

Science has determined that surface modification of soil and vegetation can increase temperatures. Large amounts of soil and vegetation reduced to build city streets, homes and businesses increase temperatures. Any city with significant amounts of surface modification experiences increased urban temperatures, whether its natural climate is temperate, tropical, warm or arid (Harlan, Brazel, Prashad, Stefanov, \& Larsen, 2006). Excessive heat lingers in urban areas well past daytime, and temperatures remain elevated into evenings and nights. Nighttime elevation of temperatures causes the most harm to urban dwellers. This increase in temperature within urban cores, when compared to adjacent rural and suburban areas, has been coined as the urban heat island or UHI. The UHI can negatively affect quality of life for urban dwellers. Excessive heat can harm individual health and wellbeing, especially individuals in temperate climates not acclimated to long intervals of excessive heat or vulnerable populations such as elders, children and people without access to air conditioning (Harlan et al., 2006).

Until recently, research and information on urban heat islands could not be found in journals on human services or social sciences as disciplines such as meteorology appeared to study UHI's and their impacts on communities. However, this has changed within the last two decades. The twenty-first century has led to growing interest and awareness of how temperature can affect human experiences. Recent research in the social sciences identify that urban heat islands appear to unjustly effect marginalized populations (Harlan et al., 2006).

\section{SCIENCE OF THE URBAN HEAT ISLAND}

There are three catalytic characteristics of cities that contribute to the UHI: surface modification, building density and population. While UHI occurs in all urban cores, variations in intensity are found due to season, geography and climate. When urban areas

Billy Hamilton, BSW, is a law student at the William Mitchell College of Law in St. Paul, MN and Christina L. Erickson, Ph.D., is an Associate Professor in the Department of Social Work at Augsburg College in Minneapolis, MN. 
develop, open-land and vegetation are replaced by industrial landscapes and infrastructure which include: buildings, skyscrapers, houses, cement sidewalks and paved roads. These structures absorb heat and subsequently warm their surroundings. The Environmental Protection Agency summarizes the source of the urban heat phenomenon, "Surfaces that were once permeable and moist [are now] impermeable and dry" (Climate Protection, 2008, p. 2). Impermeable surfaces (such as stone, asphalt, brick and concrete) tend to be dark in color (for example, gray concrete, black tar roads, dark shingles) and they absorb solar energy at faster rates than vegetation and consequently warm their surroundings. The darker the surface landscape, the higher the rate at which it absorbs energy. The more surface energy absorbed, the more heat is released into the atmosphere.

Building density also contributes to the increased city temperatures. The majority of most buildings' surface area do not face open air or spaces, instead they generally face other warm buildings with heat becoming trapped in the city. The trapped heat is then released during nocturnal times (at dusk and at night). Therefore, cities become efficient heat incubators well past dusk (Oke, 1997). This peak in temperature is most pronounced within 3 to 5 hours after sunset. The experienced elevated urban temperature, when compared to surrounding rural areas, is what constitutes an Urban Heat Island.

The size and population of the urban area will also determine the power and strength of the UHI. On an average night, cities with populations over one million can experience large differences in temperature, anywhere from $5^{\circ} \mathrm{F}$ to $20^{\circ} \mathrm{F}$ (Oke, 1997). More importantly, as population rates increase in urban areas this difference in temperature is expected to grow. For example, including data during its period of urbanization from 1948 to 2000, Baker and colleagues (2002) recorded an increase of minimum temperatures in Phoenix, Arizona. Of particular significance is the Sky Harbor Airport where, "the average daily minimum temperature...increased by $5.0^{\circ} \mathrm{C}$ between 1948 and 2000 and the average daily average temperature rose by $3.1^{\circ} \mathrm{C}^{\prime}$ (p. 191). Such elevated temperatures linger into the evenings and nights, when communities normally anticipate relief.

Urban heat islands also significantly lower the quality of water through thermal pollution. Roofs, pavements, buildings or landscapes that reach " 50 to $90^{\circ} \mathrm{F}$ ( 27 to $50^{\circ} \mathrm{C}$ ) higher than air temperatures" transfer heat to water and increase storm water runoff. On average, runoff from urban areas tend to be " $20-30^{\circ} \mathrm{F}\left(11-17^{\circ} \mathrm{C}\right)$ warmer" than runoff from rural areas (Climate Protection, 2008, p. 15). Sewers release the heated runoff into streams, ponds, lakes and rivers. The increased temperature negatively affects these aquatic ecosystems. The majority of aquatic plants and life are especially sensitive to immediate changes in temperature. As a result, various types of aquatic life can encounter shock or die. The carcasses create bastions of bacteria contaminating drinking water. For low-income, warm, urban neighborhoods with streams and ponds, this does not bode well. 


\section{EFFECTS ON HUMANS}

\section{Children}

Children, especially infants, are in critical stages of biological development that make them ill-equipped to deal with heat stress. According to Bartlett (2008), "Their more rapid metabolisms, immature organs and nervous systems, developing cognition, limited experience and behavioral characteristics" explain why children are "more likely to have long-term repercussions than...adults" as a result of heat stress (p. 502).

Children are faced with higher rates of vulnerability than adults to respiratory-borne illness and, in some parts of the country, vector-borne illness (Bullard, 2005). Given that internal organs develop during infancy and that heat islands perpetuate an increase of pollutants in the air, children are among the most vulnerable to respiratory borne illnesses like asthma. For children of low-income families unable to afford treatment, this is especially dangerous and detrimental to a child's biological and cognitive development. For example, in the urban community of Waterfront South, New Jersey, a community described as a "commercial corridor... with numerous industrial sites," administrators at one of the community's elementary schools report that "almost one-quarter of the students have asthma” (pp.128-129).

Children are disproportionately more vulnerable to heat stroke than adults because their thermoregulatory system, the system responsible for cooling the human body, is underdeveloped (Casa, Clarkson, \& Roberts, 2005). Therefore, children are more sensitive to prolonged and dramatic increases in temperature. They also maintain a significantly decreased rate of sweat per surface area of the human body, making it difficult to adapt to heat stress. Thus, children are anatomically prone to absorb heat from hot environments at high rates because of "large surface area to body mass ratio" (p.122). Prolonged elevation of temperatures into evening and nighttime hours perpetuates their risk and vulnerability to heat related illness. Between 1979 and 1999, the most recent national data available from the CDC, $4 \%$ of weather related deaths due to heat were of children (Centers for Disease Control and Prevention, 2003). This low number may likely be due to the fact that children are cared for and monitored by adults. Elders, on the other hand, are less likely to have someone watching over them.

\section{Elders}

Elders are vulnerable to heat stress. In the most recent national data, $45 \%$ of deaths were to individuals over the age of 65 (Centers for Disease Control and Prevention, 2003). Although thermoregulatory systems of the elders are developed, they may be damaged or impaired. Elders are more "susceptible to heat related illness...because they are not often able to maintain hydration" (Casa et al., 2005, p. 122). Basu and Samet (2002) find that the elders, like children, have a high sweat threshold that prevents their bodies from adapting to increases in temperature. Another variable that makes elders more susceptible to heat related illness and death can be explained by consumption of prescription medications. Basu and Samet (2002) report that "persons with chronic diseases of the heart or lungs may be more susceptible to the effects of high ambient temperatures, especially if they take certain medications (e.g., diuretics, beta blockers, 
and tranquilizers)" (p. 1219). These medications can "limit adaptive responses" to the body (i.e. crippling the body's ability to sweat and cool itself in high temperatures). In light of increased temperatures during evening and nighttime hours, it is not surprising that the majority of people dying from heat related illness (heat stroke or exhaustion) in the United States are elder persons over the age of 65 (Basu \& Samet, 2002).

One would think that elders in mild and temperate climates are immune from heat stress. This may be the case for suburban and rural dwellers, unfortunately not for those residing in dense areas of northern cities. Harlan and colleagues (2006) show, "More deaths are attributed to heat in temperate climates than in warm climates because people in temperate zones are less acclimated to high temperatures” (p. 2847). Even elders residing in temperate urban climates cannot escape the fatal heat stressors resulting from the UHI.

Another reason elders are susceptible to heat stress is because many live alone and lack the necessary resources to cope with heat related stress. In Chicago during the summer of 1995, one of the worst heat waves to ever hit the city claimed many lives and attracted global press. There were 525 Chicagoans deaths that "were medically confirmed as 'heat related' (Klinenberg, 1999, p. 255). Of those 525 deaths, 73\% were elders over the age of 65. Most notably "the death rate for seniors above 65 was 16 times higher than the rate for those under 65” (Klinenberg, 1999, pp. 255-256).

\section{Low-Income Persons}

During the summertime, urban heat islands create a myriad of unmanageable consequences for low-income peoples and families. Increased energy consumption and emissions of pollutants bolster heat-related illnesses and contaminate drinking water. While businesses and the middle and upper class are safely nestled inside air-conditioned spaces, many low-income persons cannot afford to turn on, let alone own, airconditioning units.

The effects are deadly and according to Klinenberg (1999), the majority of deaths from the heat wave that hit Chicago were in "low-income, elderly, and African American...regions of the metropolis" (p. 250). These areas were also the areas with the recorded highest temperature, "those hit hardest by the heat-wave" (Klinenberg, 1999, p. 250). Klinenberg also concludes that income was a contributing factor to 700 mortalities reporting that, "of the fifteen community areas with the highest death rates during the heat wave, eleven contained unusually high proportions of people living below half of the official poverty line...In addition...[to having] high rates of seniors living alone" (1999, pp. 254-255).

\section{URBAN HEAT ISLANDS AND SOCIAL AND ENVIRONMENTAL JUSTICE}

The United States Environmental Protection Agency's (EPA) definition of environmental justice includes "the fair treatment and meaningful involvement of all people regardless of race, color, national origin, or income with respect to the development, implementation, and enforcement of environmental laws, regulations, and 
policies" (2011). To further clarify, fair treatment "means that no group of people, including racial, ethnic, or socioeconomic groups, should bear a disproportionate share of the negative environmental consequences resulting from industrial, municipal and commercial operations...” (Center for Disease Control, 2008). Low-income persons, children and elders do indeed bear a disproportionate share of the negative environmental consequences and lack the resources to cope with heat stress and elevated nighttime temperatures. This environmental injustice is an issue within the purview of social work, as those most seriously affected lack the biological, social and/or material resources to cope with the effects of the heat island.

Ruddell, Harlan, Grossman-Clarke, and Buyantuyev (2010) established that the effects of urban heat can be immediate and fatal. They concluded that "the types of people most vulnerable to risk of exposure to extreme temperatures are minorities, elderly, and low income residents" (p. 199). Using available census data in the city of Phoenix, Ruddell and colleagues (2010) found that "median household income for the high Heat Intensity Class was just over half the income of the Low Intensity Class, and the percentage of minorities in the high intensity class was more than two times greater than the lower [Heat Intensity] class” (pp. 195-196). In other words, white, high-income earners can afford cooler temperatures and spaces at night, while ethnic minorities and the poor suffer disproportionately. Harlan and colleagues' (2006) study, which covers eight economically and ethnically distinct neighborhoods in the Phoenix metropolitan area, identifies that the UHI disproportionally affects marginalized communities and that these communities lack the necessary "material and social resources to cope with this heat” (p. 2847).

Harlan and colleagues (2006) bring this issue to light by comparing eight Phoenix neighborhoods. Two neighborhoods of significance are Black Canyon Freeway and Historic Anglo Phoenix. Black Canyon Freeway reports a median income of \$25,785 with $43.8 \%$ people living in poverty. To add, $90.9 \%$ of the neighborhood is considered an ethnic minority and $10.4 \%$ of this community's population is under 5 years of age and $6.8 \%$ is over age 65. Historic Anglo Phoenix reports a median income of $\$ 77,404$ with $9.8 \%$ living in poverty. $25.8 \%$ of the community reports being an ethnic minority and $14.4 \%$ is under age 5 and $5.8 \%$ is over age 65 (p. 2854). Here we have two neighborhoods with starkly different socio-economic and racial differences. Overall, "the difference between the lowest (Historic Anglo Phoenix) and highest average summer temperatures (Black Canyon Freeway) was 4 degrees Celsius” (p. 2853). The data suggests that "socially and economically marginalized populations [are] more likely to live in heat-stressed neighborhoods" (p. 2848). Those living in the hottest zones are more likely to be low-income persons of color. The higher the income, the more likely one is able to afford cool temperatures. The wealthy have power over the effects of the heat island whereas families of low-income do not. We speculate that families of low-income are fiscally and geographically unable to develop vegetative landscapes on or around their properties and lack the resources to develop "cool” buildings.

Because heat islands increase energy demands to cool buildings, urban cities report higher amounts of emissions from power plants and thus higher occurrences of smog formation (Heat Island Group, 2000). This translates into, "Steadily increasing downtown 
temperatures over the last several decades which means that 5 to 10 percent of community-wide demand for electricity is used to compensate for the heat island effect" (Climate Protection, 2008, p. 13). Smog increases with temperatures (Heat Island Group, 2000).

There is an increasingly clear link between heat islands and neighborhoods with higher ratios of low-income persons, elders and children. There is also a demonstrated lack of material and physiological resources to cope with the effects of heat islands. Revisiting the 1995 heat wave of Chicago offers us the chance to review responses to serious Urban Heat Island issues and offers solutions to future social work interventions. The 1995 heat wave of Chicago was fatal for a number of marginalized persons. Klinenberg (1999) blames the lack of organization and activation of local, state and federal organizations on the high number of deaths of for these groups:

During the heat wave several city departments failed to provide services that, had they been activated, would have saved hundreds of lives. The Police Department neglected to activate the local units designed to assist seniors, even though the heat wave represented precisely the kind of situation in which they would have been effective...The Fire Department, which is responsible for the office of Emergency Preparedness and Disaster Services, has no mechanism for issuing a heat emergency. The Department of Human Services did little to contact isolated seniors to warn them of the dangers of the climate, nor did it provide adequate transportation and security to help vulnerable residents...The Department of Public Health had no mechanism for coordinating emergency medical services...Throughout the city, public agencies rejected offers from volunteers because they had no idea what to do with them (p. 257).

Klinenberg's (1999) investigation paints a clear picture of what failed at the city and state level. It is important to note that the Environmental Protection Agency (EPA) does not offer direct emergency help for heat island disasters like that in Chicago; rather, the national EPA focuses on producing literature and directing communities to local and state preventative initiatives to alleviate the effects of the UHI. A full list of these initiatives is listed on the EPA website. Unfortunately, less than half of the states in the U.S. are represented in these initiatives (EPA, 2010). However, the website allows people and agencies to submit state and local initiatives. Although the EPA has made strides to organize and coordinate efforts online, many local and municipal organizations lack structure and resources to adequately respond.

\section{INTERVENTION METHODS FOR SOCIAL WORKERS}

Social workers can focus intervention efforts to accomplish two goals. First, they can further efforts to mitigate the UHI's development (interventions to promote positive institutional change), especially given our current understanding of climate change. Second, they can improve emergency responses and coping methods to heat waves and lingering nighttime temperature hikes from the UHI (interventions to promote improved residual policies). 


\section{Organizing and Partnering to Mitigate Urban Heat Islands}

Social workers can help communities or municipalities to gain an understanding of the UHI. They can organize meetings in dense urban areas. Communities can identify who possesses expertise in community planning, advocacy and organization, connections with local government officials and city planners, or who is equipped with legal expertise. Groups can begin to reach out to other social and environmental groups with similar agendas such as the Sierra Club, The Nature Conservancy, The Audubon Society or other local and national groups that have invested in curbing the effects of climate change or maintaining urban vegetation. By garnering attention and support, they are able to empower themselves to elect leaders with likeminded platforms and to influence change at the local level. Fiscally, practical and structurally viable options to alleviate and eliminate the UHI and its negative effects upon marginalized persons include: subsidizing community gardens and tree planting, supporting and increasing vegetation, halting and reversing increased surface modifications, cool roof installments, and permeable and cooling pavement initiatives. Group members can then collaborate with the EPA to publicize, coordinate and organize their initiatives on the EPA's UHI website.

Plants and trees do mitigate the UHI. Plants and trees are able to intercept solar energy before it hits buildings and paved surfaces. Vegetation cools air through the process known as evapotranspiration. Trees also disrupt and block people and buildings from freezing winds during the winter. Although it depends upon climate, region and geography, the Environmental Protection Agency (EPA) (2012) reports that cities can save money by implementing full-scale vegetation initiatives. Vegetation and trees also reduce the thermal heat absorbed by storm runoff which also preserves aquatic ecosystems in urban vicinities. Tree planting programs can be cost effective and incentives should be offered to communities that plant them.

In one experiment conducted in Florida by Parker (1981, as cited in Akbari, 2001), measurements of energy consumption were taken before and after adding vegetation (trees, grass, bushes and shrubs) in the immediate area of an urban building. The result was a 50\% savings in cooling costs (p. 12). This also decreases the amount of smog released into the atmosphere. First, trees absorb carbon dioxide and release oxygen through the process of photosynthesis. Second, dwellings require less energy to cool and thus less electricity is demanded and used from power plants. The results are undeniably beneficial. If implemented on a national level, savings could be limitless (Environmental Protection Agency, 2012).

Social workers can advocate for vegetation initiatives at the city or county level. Programs such as that found in the city of Minneapolis, in partnership with Tree Trust, is one example. For a small fee $(\$ 15-\$ 25)$ residents can purchase a tree. In Austin Texas, efforts to mitigate UHI effects have resulted in "NeighborWoods," an effort to grow the urban forest. A non-profit project provided by TreeFolks provides free trees to families living in specified areas if homeowners agree upkeep the tree (www.http://www.ci.austin.tx.us/urbanheatisland/trees.htm). Projects such as these are good models to emulate in communities. 
Another step to mitigate heat stress in vulnerable communities is through the use of cool roofs and high-albedo (reflective) building material. During the summertime, dark roofs absorb high rates of solar energy and, as a result, warm the atmosphere and the building beneath the roof. Roofs covered with a white coating are engineered to reflect significantly greater amounts of solar energy, thus decreasing absorption of heat. Aside from applying a particular white acrylic paint or elastomer designed for roofs, these cool roofs do not require any additional costs for maintenance. In one study conducted in an urban community of Atlanta, Georgia, a school rooftop with an unpainted, galvanized roof was painted with a white acrylic paint. The following year the school reported a $75 \%$ decrease in cooling costs (Akbari, 2001).

Much like cool roofs, converting dark smooth pavements into cool high-albedo pavements increases reflection of solar energy back into space. This decreases the amount of heat trapped inside the urban ecosystem while alleviating the associated fiscal costs of cooling buildings. When these initiatives are combined they have a significant positive impact upon communities. Another benefit of cool, reflective pavements includes a decrease in the demand for electricity and number of streetlights in urban areas. Because cool surfaces reflect more light, the visibility for motorists, bicyclists and pedestrians on sidewalks and streets is significantly improved at dusk and at night. Cool pavements and sidewalks curb the effects of both light pollution and energy consumption.

There is a diversity of ways to mitigate the UHI. Every community's model will be different. As pointed out by a study that evaluated the effectiveness of mitigation strategies in the city of New York, cities ought to "implement urban heat island mitigation strategies appropriate to conditions in individual neighborhoods and communities” (Rosenzweig et al., 2006, p. 4). For example, New York City has more skyscrapers and buildings than the city of Minneapolis. It would make more sense for activists in New York City to first focus on developing initiatives for high-albedo roofs and pavements. In Minneapolis, a city with more open space and fewer buildings, it would make more sense to develop initiatives to preserve unmodified soil and to implement more urban vegetation. By gathering a diversity of knowledgeable, specialized persons at the local level can tailor initiatives to the needs of each urban area.

\section{Organizing and Partnering to Cope with Urban Heat Island Effects}

Because we understand the strategies listed above require significant amounts of time, social workers will need to help vulnerable persons adapt to heat stress in the immediate future. Efforts can help curb mortality rates until heat islands are reduced. Plans must be designed according to each community's respective demographics and infrastructure. As no two urban neighborhoods and communities are the same, adaptive plans should be localized to the community culture (Rosenzweig et al., 2006).

Social workers must organize at local levels by reaching out to the medical, mental health and human service communities to compile resources and information. Multilingual educational outreach with pragmatic, practical tips on how to prevent heatstroke and exhaustion is a first step. Information ought to include suggestions on how to prepare for extreme heat, such as: Stay indoors as much as possible, drink plenty of water, cover 
windows with tin foil or outdoor awnings (this can reduce the amount of heat that enters a home by $80 \%$ ), spend the day at public facilities (like libraries or schools), limit intake of alcohol, stay on the lowest floor and out of sunshine if air conditioning is not available (FEMA, 2010). Pamphlets should also include charts that illustrate the symptoms of heat related illness (heat cramps, sunburn, heat exhaustion and heat stroke) so people know when to go to the hospital.

Literature should also include locations of and directions to free cool zones for those unable to afford air conditioning or those especially vulnerable to extreme heat, like children and elderly persons. What can professionals do if their city does not already have designated cool zones? They can collaborate with city councils, law-enforcement agencies and fire departments to designate these zones. Libraries, public schools and community centers make great locations for cool zones. These zones should be within neighborhoods with higher density of low-income persons, elders and children or in close proximity.

In order to make sure the above strategies are correctly implemented, let us underscore past organizational errors that proved to be fatal. A key failure during the Chicago heat wave of 1995 was the lack of organization between agencies and lowincome persons, elders and children. For example, the Department on Aging did not activate its own emergency measure to contact isolated elders living alone to warn them

of heat stress. Volunteers were "turned away from local agencies and the Department of Human Services, the Fire Department and the Office of Emergency Preparedness and Disaster Services did not issue a heat emergency” (Klinenberg, 1999, p. 257). Recognizing these failures is the first step to making certain they do not happen again. Second, professionals must work with local agencies to decide the following: when to declare emergency heat waves, who can declare them, how to inform the public, where to implement free cooling zones and how to provide transportation to these cooling stations. Social workers can collaborate with urban hospitals to prepare staff to accommodate for more patients during heat emergencies. These efforts will help save lives.

\section{FUTURE IMPLICATIONS}

Social workers have the potential to help eliminate the deleterious effects of the UHI and help empower vulnerable community members. However, we can expect many obstacles to prevent us from making change. In light of the current national political climate and anti-government sentiment, social workers will face an uphill battle. However, the battle is necessary, as increasing nighttime temperatures across the nation are breaking records every year. As reported in the Washington Post, "Preliminary figures from the Northeast Regional Climate Center at Cornell University show 28 cities from Washington, D.C., to Caribou, Maine, set record highs for average temperature from March through August” (Weil, 2010). These estimates do not bode well for those most vulnerable to heat stress. The social work profession's applied and social justice strategies for intervention, in partnership with other groups, can reduce mortality and morbidity rates of marginalized persons as a result of the rise in the UHI. 


\section{References}

Akbari, H. (2001). Energy saving potentials and air quality benefits of urban heat island mitigation. Washington, DC: United States Department of Energy, 12-18. Retrieved from Department of Energy's Office of Scientific and Technical Information: http://www.osti.gov/bridge/purl.cover.jsp;jsessionid=FE1D82F979614A4753B7A64 8A39FCE2F?purl=/860475-UlHWIq/

Baker, L. A., Brazel, A. J., Selover, N., Martin, C., McIntyre, N., Steiner, F. R. et al. (2002). Urbanization and warming of Phoenix (Arizona, USA): Impacts, feedbacks and mitigation. Urban Ecology, 6, 183-203.

Bartlett, S. (2008). Some likely impacts of climate change [chart]. Climate change and urban children: Impacts and implications for adaptation in low- and middle-countries. Environment and Urbanization, 20, 501-515. Retrieved from http://eau.sagepub.com/content/20/2/501.full.pdf + html

Basu, R., \& Samet, J.M. (2002). An exposure assessment of study of ambient heat exposure in an elderly population in Baltimore, Maryland. Environmental Health Perspectives, 12, 1219-1223. Retrieved from http://www.ncbi.nlm.nih.gov/pmc/articles/PMC1241109/pdf/ehp0110-001219.pdf

Bullard, R. D. (2005). The quest for environmental justice: Human rights and the politics of pollution ( $1^{\text {st }}$ ed.). San Francisco: Sierra.

Casa, D., Clarkson, P., \& Roberts, W. (2005). American college of sports medicine roundtable on hydration and physical activity: Consensus statements. Current Sports Medicine Reports, 4, 115-127. Retrieved from http://www.coachingireland.com/files/american_college.pdf

Center for Disease Control. (2008). Environmental justice. Atlanta, GA: Office of Minority Health \& Health Disparities. Retrieved August 17, 2011, from http://www.cdc.gov/omhd/amh/EJ.htm

Centers for Disease Control and Prevention. (2003). Heat related deaths - Chicago, Illinois, 1996-2001 and, United States, 1979-1999. Morbidity and Mortality Weekly Report, 52, 610-613.

Climate Protection Partnership Division. (2008). Urban heat islands: Compendium of strategies: Urban heat island basics, 1-17. Washington, DC: United States Environmental Protection Agency. Retrieved from http://www.epa.gov/hiri/resources/pdf/BasicsCompendium.pdf

Environmental Protection Agency. (2010). Where you live. Washington, DC: Author. Retrieved August 10, 2010, from http://yosemite.epa.gov/gw/statepolicyactions.nsf/webpages/HIRI_Initiatives.html

Environmental Protection Agency. (2011). Environmental justice. Washington, DC: Author. Retrieved from http://www.epa.gov/environmental justice/ 
Environmental Protection Agency. (2012). Trees and vegetation. Washington, DC:

Author. Retrieved from http://www.epa.gov/hiri/mitigation/trees.htm

Federal Emergency Management Agency. (2010). Are you ready? Washington, DC:

United States Department of Homeland Security. Retrieved from http://www.fema.gov/areyouready/heat.shtm

Harlan, S. L., Brazel, A. J., Prashad, L., Stefanov, W. L., \& Larsen, L. (2006).

Neighborhood microclimates and vulnerability to heat stress. Social Science \& Medicine, 63, 2847-2863.

Heat Island Group. (2000). Cool science: Urban heat island. Retrieved from http://heatisland.lbl.gov/coolscience/cool-science-urban-heat-island

Klinenberg, E. (1999). Denaturalizing disaster: A social autopsy of the 1995 Chicago heat wave. Theory and Society, 28, 239-295. Retrieved from http://www.umaryland.edu/healthsecurity/mtf_conference/Documents/Additional\%2 0Reading/Session\%203/A\%20Social\%20Autopsy\%20of\%20the\%201995\%20Heat\% 20Wave.pdf

Oke, T. R. (1997). Urban climates and global environmental change. In R. D. Thompson \& A. Perry (Eds.), Applied climatology: Principles and practice (pp. 273-287). New York: Routledge.

Ruddell, D. M., Harlan, S. L., Grossman-Clarke, S., \& Buyantuyev, A. (2010). Risk and exposure to extreme hear in microclimates of Phoenix, AZ. In P. S. Showalter \& Y. Lu (Eds.), Geotechnologies and the environment ( $2^{\text {nd }}$ ed., pp. 179-202). DOI 10.1007/978-90-481-2238-7_9

Rosenzweig, C., Solecki, W., Parshall, L., Gaffin, S., Lynn, B., Goldberg, R., Cox, J., \& Hodges, S. (2006). Mitigating New York City's heat island with urban forestry, living roofs, and light surfaces. A report to the New York State Energy Research and Development Authority, 1-4. Retrieved from http://www.giss.nasa.gov/research/news/20060130/103341.pdf

Weil, M. (2010, August 29). Latest heat wave could set records. The Washington Post. Retrieved from http://www.washingtonpost.com/wpdyn/content/article/2010/08/28/AR20100828038 06.html

Author note:

Address correspondence to: Billy Hamilton, BSW, Augsburg College Department of Social Work, 2211 Riverside Ave, CB 51, Minneapolis, MN 55113.

Email: William.Hamilton@alumni.augsburg.edu 